\title{
DEFICIENCY IN PARVALBUMIN, BUT NOT IN CALBINDIN D-28K UPREGULATES MITOCHONDRIAL VOLUME AND DECREASES SMOOTH ENDOPLASMIC RETICULUM SURFACE SELECTIVELY IN A PERIPHERAL, SUBPLASMALEMMAL REGION IN THE SOMA OF PURKINJE CELLS
}

\author{
G. CHEN, ${ }^{a, b 1}$ P. RACAY,,${ }^{a, d 1}$ S. BICHET, ${ }^{a, e}$ M. R. CELIO, ${ }^{a}$ \\ P. EGGLI` AND B. SCHWALLER ${ }^{\mathrm{a} *}$ \\ a University of Fribourg, Division of Histology, Department of Medicine, \\ University of Fribourg, 14, chemin du Musée, CH-1705 Fribourg, Swit- \\ zerland \\ ${ }^{b}$ McGill University Health Center, Calcium Research Laboratories, \\ Royal Victoria Hospital Room H4.72, 687 Pine Avenue West, Mon- \\ treal, QC, Canada H3A $1 A 1$ \\ 'University of Bern, Department of Anatomy, Bühlstrasse 26, CH-3012 \\ Bern, Switzerland \\ ${ }^{d}$ Comenius University, Jessenius Faculty of Medicine, Institute of Bio- \\ chemistry, Mala Hora 4, SK-03601 Martin, Slovakia \\ ${ }^{\circ}$ Friedrich Miescher Institute for Biomedical Research, Maulbeer- \\ strasse 66, CH-4058 Basel, Switzerland
}

\begin{abstract}
The $\mathrm{Ca}^{2+}$-binding proteins parvalbumin (PV) and calbindin D-28k (CB) are key players in the intracellular $\mathrm{Ca}^{2+}$-buffering in specific cells including neurons and have profound effects on spatiotemporal aspects of $\mathrm{Ca}^{2+}$ transients. The previously observed increase in mitochondrial volume density in fast-twitch muscle of PV $-I-$ mice is viewed as a specific compensation mechanism to maintain $\mathrm{Ca}^{2+}$ homeostasis. Since cerebellar Purkinje cells (PC) are characterized by high expression levels of the $\mathrm{Ca}^{2+}$ buffers $\mathrm{PV}$ and $\mathrm{CB}$, the question was raised, whether homeostatic mechanisms are induced in PC lacking these buffers. Mitochondrial volume density, i.e. relative mitochondrial mass was increased by $40 \%$ in the soma of PV-I- PC. Upregulation of mitochondrial volume density was not homogenous throughout the soma, but was selectively restricted to a peripheral region of $1.5 \mu \mathrm{m}$ width underneath the plasma membrane. Accompanied was a decreased surface of subplasmalemmal smooth endoplasmic reticulum (sPL-sER) in a shell of $0.5 \mu \mathrm{m}$ thickness underneath the plasma membrane. These alterations were specific for the absence of the "slow-onset" buffer PV, since in CB-I- mice neither changes in peripheral mitochondria nor in SPL-sER were observed. This implicates that the morphological alterations are aimed to specifically substitute the function of the slow buffer PV. We propose a novel concept that homeostatic mechanisms of components involved in $\mathrm{Ca}^{2+}$ homeostasis do not always occur at
\end{abstract}

${ }^{1}$ G.C. and P.R. equally contributed to the work.

${ }^{*}$ Corresponding author. Tel: +41-0-26-300-85-08; fax: +41-0-26300-97-32.

E-mail address: Beat.Schwaller@unifr.ch (B. Schwaller).

Abbreviations: $\mathrm{CaBP}, \mathrm{Ca}^{2+}$-binding protein; $\left[\mathrm{Ca}^{2+}\right]_{\mathrm{i}}$, intracellular $\mathrm{Ca}^{2+}$ concentration; $\left[\mathrm{Ca}^{2+}\right]_{\mathrm{m}}$, mitochondrial $\mathrm{Ca}^{2+} ; \mathrm{CB}$, calbindin $\mathrm{D}-28 \mathrm{k}$; CICR, $\mathrm{Ca}^{2+}$-induced $\mathrm{Ca}^{2+}$ release; COX I, cytochrome c oxidase I; ER, endoplasmic reticulum; NCS, neuronal calcium sensor protein; PC, Purkinje cells; PMCA, plasma membrane $\mathrm{Ca}^{2+}$-ATPase; PV, parvalbumin; SDS-PAGE, polyacrylamide gel electrophoresis; SERCA, sarcoendoplasmic reticulum $\mathrm{Ca}^{2+}$-ATPase; sPL-sER, subplasmalemmal smooth endoplasmic reticulum; WT, wildtype. the level of similar or closely related molecules. Rather the cell attempts to restore spatiotemporal aspects of $\mathrm{Ca}^{2+}$ signals prevailing in the undisturbed (wildtype) situation by subtly fine tuning existing components involved in the regulation of $\mathrm{Ca}^{2+}$ fluxes.

Key words: calcium-binding, buffers, EF-hand, homeostasis, morphology.

$\mathrm{Ca}^{2+}$ ions are such ubiquitous second messengers that meaningful information must be contained in the subtle spatiotemporal aspects of $\mathrm{Ca}^{2+}$ transients. A complex machinery of $\mathrm{Ca}^{2+}$ entry and release systems, mobile and immobile $\mathrm{Ca}^{2+}$ buffers, transient $\mathrm{Ca}^{2+}$-storage devices and $\mathrm{Ca}^{2+}$-extrusion systems governs the shape and spreading of intracellular $\mathrm{Ca}^{2+}$ transients (Berridge et al., 2003). Affinities, kinetics of binding and release of $\mathrm{Ca}^{2+}$ ions, the relative mobility and the geometrical distribution of all components, that is, the interplay between these systems finally shapes the spatiotemporal aspects of a $\mathrm{Ca}^{2+}$ signal. Cerebellar Purkinje cells (PC) are characterized by extensive $\mathrm{Ca}^{2+}$ signaling in somata, dendrites and spines elicited by either climbing fiber or parallel fiber stimulation. Following depolarization-evoked rises in the intracellular $\mathrm{Ca}^{2+}$ concentration $\left(\left[\mathrm{Ca}^{2+}\right]_{\mathrm{i}}\right)$ in the PC somata, endoplasmic reticulum (ER) and plasma membrane $\mathrm{Ca}^{2+}$ pumps and the $\mathrm{Na}^{+}-\mathrm{Ca}^{2+}$ exchanger contribute to PC $\left[\mathrm{Ca}^{2+}\right]_{i}$ clearance (Fierro et al., 1998). Since these systems only accounted for approximately $60 \%$ of total $\mathrm{Ca}^{2+}$ clearing, mitochondria were additionally postulated to play a role. These organelles have a high capacity to take up $\mathrm{Ca}^{2+}$, but affinity and the speed of uptake were previously considered too low to sequester $\mathrm{Ca}^{2+}$ under physiological conditions in neurons (Carafoli, 2002). A role for mitochondria in the presynaptic regulation of $\mathrm{Ca}^{2+}$ transients was demonstrated in the calyx of Held (Billups and Forsythe, 2002). With a half-rise time of approximately $40 \mathrm{~ms}$, mitochondrial $\mathrm{Ca}^{2+}\left(\left[\mathrm{Ca}^{2+}\right]_{\mathrm{m}}\right)$ rose with a short delay when compared with $\left[\mathrm{Ca}^{2+}\right]_{i}$ rises. Mitochondrial depolarization abolished rises in $\left[\mathrm{Ca}^{2+}\right]_{\mathrm{m}}$ and as a consequence slowed the removal of $\left[\mathrm{Ca}^{2+}\right]_{i}$ by more than twofold.

The role of mobile $\mathrm{Ca}^{2+}$ buffers in the modulation of $\mathrm{Ca}^{2+}$ transients and thus in processes such as modulation of synaptic transmission (facilitation and depression) has recently regained much interest (Caillard et al., 2000; Blatow et al., 2003; Vreugdenhil et al., 2003). PC have an 
exceptionally high endogenous $\mathrm{Ca}^{2+}$-buffering capacity (Fierro and Llano, 1996) due to high expression levels of parvalbumin (PV) and calbindin D-28k (CB) (Celio, 1990). The two proteins differ in their number of $\mathrm{Ca}^{2+}$-binding sites; two for $\mathrm{PV}$ and four for $\mathrm{CB}$, but probably more importantly in their $\mathrm{Ca}^{2+}$-binding kinetics (Schwaller et al., 2002). $\mathrm{PV}$ is a slow-onset $\mathrm{Ca}^{2+}$ buffer (Lee et al., 2000), while $\mathrm{Ca}^{2+}$-binding to $\mathrm{CB}$ is faster (Nagerl et al., 2000). Both proteins contribute to the modulation of parallel fiberevoked $\mathrm{Ca}^{2+}$ transients in PC dendrites (Schmidt et al., 2003b). We had hypothesized that elimination of PV and CB might induce compensation mechanisms in PC to cope with their absence. Such changes did not occur at the level of other $\mathrm{Ca}^{2+}$-binding proteins (CaBPs) (Schmidt et al., 2003 b), but involved morphological alterations. An increase in PC spine length and volume was specifically induced by elimination of CB (Vecellio et al., 2000), while elimination of $\mathrm{PV}$ in fast-twitch muscles led to an approximately twofold increase in the mitochondrial volume density without affecting fiber surface size (Chen et al., 2001). We set out to test whether organelles (ER, mitochondria) implicated in $\mathrm{Ca}^{2+}$ homeostasis in PC somata and dendrites are affected by elimination of cytosolic $\mathrm{Ca}^{2+}$ buffers.

\section{EXPERIMENTAL PROCEDURES}

\section{Preparation of tissue for electron microscopy}

Four groups of mice were analyzed: PV-I- (Schwaller et al., 1999), CB $-/-$ (Airaksinen et al., 1997), PV $-/-C B-/-$ (Vecellio et al., 2000 ) and wildtype (WT), all with a mixed C57BL/6J $\times 129$ background. All animal experiments were performed with permission of the local animal care committee and according to the present Swiss law and the European Communities Council Directive of 24 November 1986 (86/609/EEC); both the number of animals used and their suffering were kept to a minimum. Three or four female mice (3-5 months old) were analyzed per genotype. Animals were killed by an overdose of $4 \%$ chloral hydrate and then perfused with Karnovsky reagent $(80 \mathrm{mM}$ sodium cacodylate, $\mathrm{pH} 7.3$, containing $2 \%(\mathrm{w} / \mathrm{v})$ paraformaldehyde, $2.5 \%(\mathrm{v} / \mathrm{v})$ glutaraldehyde and $\left.0.2 \mathrm{mM} \mathrm{CaCl}_{2}\right)$. Brains were postfixed by immersion overnight at $4{ }^{\circ} \mathrm{C}$, the cerebella cut in half, then washed twice in $0.1 \mathrm{M}$ sodium cacodylate (15 min), postfixed for two hours in $1 \%$ osmium tetroxide in $0.6 \mathrm{M}$ veronal-Naacetate, dehydrated and finally embedded in Epon. From each cerebellar half, i.e. from two tissue blocks per animal, ultrathin sections oriented perpendicularly to the surface of the cerebellar cortex were examined and documented in a Philips EM 400 and used for morphometric analysis.

\section{Morphometric analysis of PC somata}

All morphometric measurements and analyses were performed on randomly numbered electron micrographs with the experimenter not knowing the genotype of the mouse source of the analyzed images. The identity of individual micrographs for the grouping according to genotype and for the statistical analyses was only revealed after completion of all the counting procedure. In each consecutive frame of a 200 square mesh grid (starting at a random point) an electron micrograph (up to a total of 30 per cerebellum) of a PC soma-if present and sectioned approximately through the center of the cell, respectively nucleus - was taken and the volume density of mitochondria in the cell cytoplasm (i.e. ratio of volume of mitochondria to volume of cytoplasm) was estimated at a final magnification of $11,300 \times$ using a test system D $64(1024$ test points; Weibel, 1979). The mitochondria measurements were then repeated separately for a peripheral (area $1.5 \mu \mathrm{m}$ underneath the cell membrane) and a central region. The central region was defined as cytoplasmic region between the peripheral region and the cell nucleus.

For the estimation of the surface of the subplasmalemmal smooth endoplasmic reticulum (sPL-sER) of PC somata, a compartment of $0.5 \mu \mathrm{m}$ underneath the cell membrane was defined. No ultrastructural distinction between described junctional ER (in PC characterized by an orientation parallel to the plasma membrane and the gap to the plasma membrane filled with "fuzzy" material (Henkart et al., 1976)) and other sER compartments was attempted. In the morphometric measurements all SER structures within a shell of $0.5 \mu \mathrm{m}$ were considered for the analyses. Per cell four EM pictures were taken, covering approximately $90 \%$ of the entire circumference of the perikaryon. Using a cycloid test system (Weibel, 1979), the lengths, respectively surfaces of the cell membrane and the underlying SPL-sER within the defined compartment were estimated at a final magnification of $32,000 \times$. The results are given as a ratio of sPL-sER surface to cell membrane surface.

\section{Morphometric analysis of immunofluorescence images of PC soma and dendrites}

Free floating saggital cerebellar cryosections $(30 \mu \mathrm{m})$ obtained from 4\% PFA transcardiacally perfused mice were immunostained with antibodies against CB (CB38, 1: 4000, Swant, Bellinzona, Switzerland) and against cytochrome oxidase I (mouse monoclonal COXI; $5 \mu \mathrm{g} / \mathrm{ml}$, ID6-E1-A8, Molecular Probes, Invitrogen AG, Basel, Switzerland). Immunoreaction was revealed with fluorescently labeled anti-rabbit (FITC-conjugate, 1:100; Molecular Probes) or anti-mouse (Alexa 568-conjugate, 1:100; Molecular Probes) secondary antibodies. Sections were coverslipped with Slowfade reagent (Molecular Probes) and analyzed on a confocal microscope (Bio-Rad MRC 1024, Glattbrugg, Switzerland mounted on a Nikon Eclipse E800

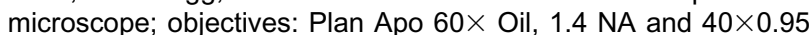
$\mathrm{NA}$ ). Off-line image analysis was carried out either with the software Imaris 4.0.5 (Bitplane, Zurich, Switzerland) or Stereo Investigator 5.0 (MicroBrightfield Inc., Williston, VT, USA). With the former, on 3D-reconstructed images from WT and PV-I- PC somata and distal dendrites, mitochondrial volumes were calculated from randomly selected regions. Alternatively, on at least three sections per stack of confocal images, morphometry was used to calculate mitochondrial fractional volume.

\section{Statistical analysis}

Student's $t$-test (unpaired, two-tailed) was used to compare values of morphometric measurements in the soma from $\mathrm{PV}-1-$, CB $-I-$ and $\mathrm{PV}-1-\mathrm{CB}-1-$ mice with those of $\mathrm{WT}$ mice. Values are expressed as means \pm S.D. $P$ values $<0.05$ were considered statistically significant. For comparison of the very heterogeneous distribution of fractional mitochondria volume in PC dendrites, the non-parametric Mann-Whitney $U$ test was applied.

\section{Semi-quantitative Western blot analysis and $\mathrm{Ca}^{2+}$ overlay blots}

Young adult male mice were deeply anesthetized by inhalation of $\mathrm{CO}_{2}$ and briefly perfused transcardially by ice-cold phosphatebuffered saline solution (PBS). Cerebella were dissected and a soluble and particulate fraction was prepared as described (Maetzler et al., 2004). Proteins (50-75 $\mu \mathrm{g})$ were separated by polyacrylamide gel electrophoresis (SDS-PAGE) and transferred on nitrocellulose membranes using a semi-dry transfer protocol. Western blots of proteins were carried out using primary antibodies against sarcoendoplasmic reticulum $\mathrm{Ca}^{2+}$-ATPase (SERCA) $2 b$ (Wuytack et al., 1989), plasma membrane $\mathrm{Ca}^{2+}$-ATPase (PMCA) 2 (clone NR2 (Filoteo et al., 1997), gift from E. Strehler), 

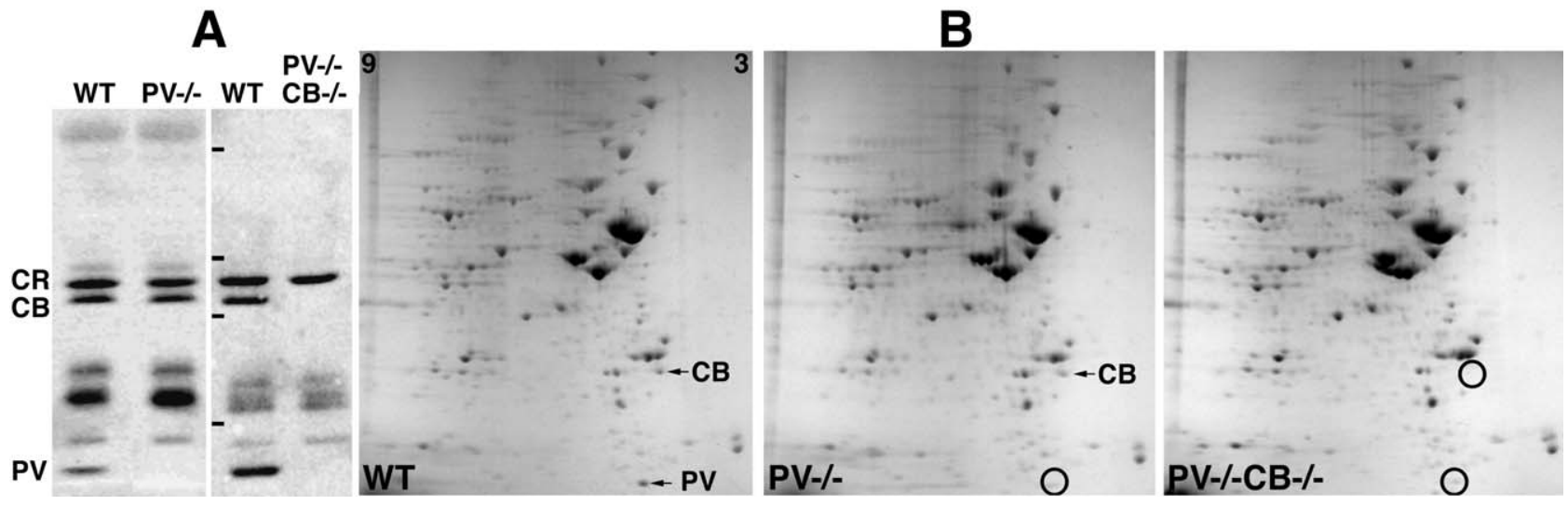

Fig. 1. (A) ${ }^{45} \mathrm{Ca}^{2+}$-overlay blot of soluble cerebellar proteins of two WT, a $\mathrm{PV}-/-$ and a $P V-/-C B-/-$ mouse. The three most intense single bands in WT are calretinin (CR; $29 \mathrm{kDa}), \mathrm{CB}(27 \mathrm{kDa})$ and PV (12 kDa). In the range of $16-24 \mathrm{kDa}$, proteins including calmodulin, and NCS are visible. Scale bars $=48,35,28$, and $20 \mathrm{kDa}$ and indicate positions of marker proteins; sizes are from top to bottom. (B) 2D-gel electrophoresis of soluble cerebellar proteins. The positions of PV and CB are marked with arrows and circles mark the corresponding areas in the knockout mice. The region between an isoelectric point of 3 and 9 is shown and the lowest part of the gel corresponds to proteins with an apparent $M_{r}$ of $10 \mathrm{kDa}$.

PMCA3 (Stauffer et al., 1995), cytochrome c oxidase I (COX I; clone 1D6-E1-A8, Molecular Probes) and actin (antibody clone ZSA1, Zymed, Stehelin \& Cie AG, Basel, Switzerland) for normalization of Western blot signals. Incubation of membranes with secondary biotinylated antibodies (Vector Laboratories, Burlingame, CA, USA; 1:10,000) and with avidin-biotin conjugated peroxidase was followed by revealing specific bands using the ECL system (Pierce, Perbio Science, Lausanne, Switzerland). For quantification, a Molecular Imager system (Bio-Rad) was used.

From the soluble fraction, proteins $(250 \mu \mathrm{g})$ were separated by SDS-PAGE (12.5\%) and electroblotted on nitrocellulose membranes. Membranes were washed (three times, $20 \mathrm{~min}$ ) in $10 \mathrm{mM}$ imidazole- $\mathrm{HCl}, 5 \mathrm{mM} \mathrm{MgCl}, 60 \mathrm{mM} \mathrm{KCl}, \mathrm{pH} 6.8$ and incubated for $10 \mathrm{~min}$ in the same solution containing $40 \mathrm{kBq} / \mathrm{ml}{ }^{45} \mathrm{CaCl}_{2}$ to label high-affinity CaBPs (Maruyama et al., 1984). After washing in $50 \%$ ethanol ( $5 \mathrm{~min}$ ), membranes were dried, and analyzed by a Molecular Imager system.

\section{Two-dimensional gel electrophoresis}

2D gel electrophoresis was performed according to Langen et al. (1997) with modifications. Samples were prepared by solubilization of either lyophilized soluble proteins or sedimented membranes in 2D sample buffer (7 M urea, $2 \mathrm{M}$ thiourea, 4\% (w/v) CHAPS, 1\% (w/v) DTE, $20 \mathrm{mM}$ Tris, $0.02 \%$ (w/v) Bromphenol Blue, $1 \mathrm{mM}$ EDTA, one tablet of protease inhibitor cocktail (Roche, Rotkreuz, Switzerland) per $10 \mathrm{ml}$ of sample buffer added just prior to use). Protein concentration was determined either by Bradford assay or Dc protein assay (Bio-Rad). Proteins (1 mg) were first separated by isoelectric focusing on Immobiline Drystrips (pH 3-10; Pharmacia, Amersham Biosciences Europe $\mathrm{GmbH}$, Dübendorf, Switzerland), followed by a separation on a linear gradient $(9-16 \%)$ polyacrylamide gel. Gels were stained by Coomassie Blue R-250.

\section{RESULTS}

\section{$\mathrm{Ca}^{2+}$ overlay blots, Western blot analysis and 2D-gel electrophoresis}

Elimination of a $\mathrm{Ca}^{2+}$ buffer protein by gene targeting might induce homeostatic mechanisms to compensate for this loss. The most obvious candidates are members belonging to the family of EF-hand CaBPs consisting of over 240 proteins (Lander et al., 2001) that potentially might replace $\mathrm{PV} . \mathrm{Ca}^{2+}$ overlay blots of cerebellar soluble pro- teins of WT, PV $-/-, \mathrm{CB}-/-$ and $\mathrm{PV}-/-\mathrm{CB}-/-$ revealed the three most prominent single bands $\left(\mathrm{M}_{\mathrm{r}}: 30,28\right.$, and 12 $\mathrm{kDa}$ ) in WT to be calretinin, CB and PV (Schmidt et al., 2003b). Lack of CaBPs, i.e. PV, CB (not shown) or both did not affect either the banding pattern or the intensities of the remaining bands, indicating no apparent upregulation of other $\mathrm{CaBPs}$ detectable with this method (Fig. 1A). Intensities of bands in the range of $16-24 \mathrm{kDa}$ including proteins such as calmodulin and neuronal calcium sensor proteins (NCS) were quite variable between extracts from different experiments as evidenced by the pattern in the two WT samples. Thus, only samples collected and prepared in parallel, from WT and transgenic mice, were qualitatively and quantitatively analyzed. Since some EFhand CaBPs, e.g. S100 proteins, are poorly detected by the above method, we tested generally for the possibility that another protein is upregulated to similar levels as PV and $\mathrm{CB}$ in the cerebellar extracts. Both soluble and particulate protein fractions from $\mathrm{WT}, \mathrm{PV}-1-$ and $\mathrm{PV}-1-$ $\mathrm{CB}-1-$ cerebella were separated by $2 \mathrm{D}$-gel electrophoresis (Figs. 1B and S1). While in WT mice, PV and CB are expressed at clearly visible levels, either one or both are absent in PV $-1-$ or double knockout mice, respectively. The weak protein signal at the position of PV in the $\mathrm{PV}-/-$ and $\mathrm{PV}-/-\mathrm{CB}-/-$ samples is not due to "residual" PV expression, since absolutely no signal on Western blots of PV $-1-$ cerebellar extracts was detected before (Caillard et al., 2000). Inspection of at least six gels (samples from three mice run in duplicates) revealed no upregulation of another protein to comparable levels as the proteins missing in the two knockout groups. Similar results were obtained for the particulate fractions from the four groups, i.e. no obvious upregulation of anther protein (data shown for WT and PV-I-, Fig. S1). Finally, we hypothesized that systems involved in $\mathrm{Ca}^{2+}$ extrusion or $\mathrm{Ca}^{2+}$ uptake into intracellular organelles might be altered in the absence of these cytosolic $\mathrm{Ca}^{2+}$ buffers. Expression levels of PMCA2 and 3, as well as SERCA2b that is highly expressed in PC (Baba-Aissa et al., 1998) 


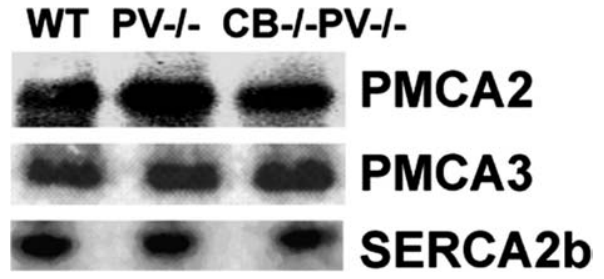

Fig. 2. Representative Western blots for the PMCA isoforms 2 and 3 and the SERCA2b. Blots were quantitatively analyzed by a Molecular Imager system and the normalized WT signals for each protein were set as 100\%; values for samples from knockout mice are expressed as mean \pm S.D. and are for PMCA2: $91 \pm 12 \%(P V-/-)$ and $99 \pm 16 \%$ (CB-I- PV-I-); $n=4$ samples/genotype. Values for PMCA3 are $98 \pm 6 \%(\mathrm{PV}-/-)$ and $94 \pm 14 \%(\mathrm{CB}-/-\mathrm{PV}-/-) ; n=5$ samples/genotype. Values for SERCA2b are $99 \pm 4 \%(P V-/-)$ and $94 \pm 15 \%$ (CB-I- PV $-/-) ; n=3$ samples/genotype. No significant differences were detected compared with the WT samples Student's $t$-test (unpaired, two-tailed)

were investigated by semi-quantitative Western blot analysis (Fig. 2). Levels of SERCA2b and both PMCA isoforms were similar in all three groups (WT, PV $-I-$, $\mathrm{PV}-/-\mathrm{CB}-/-$; Fig. 2); quantitative analysis of phosphoimager pictures using the actin signal for normalization revealed no significant differences between groups. Initial results on PMCA2, an isoform highly expressed in PC somata and dendritic spines (Stauffer et al., 1997) revealed small, but not statistically significant differences at the protein level. Yet at the mRNA level, RT-PCR signals were found unaltered in all genotypes (data not shown).

\section{Morphometric analysis of mitochondrial volume density}

Morphometric analysis of PC somata electron micrographs revealed that total mitochondrial volume density was increased by about $40 \%$ in PC of PV $-1-$ mice (Table 1). In contrast, elimination of $\mathrm{CB}$, also highly expressed in $\mathrm{PC}$, had no effect on mitochondrial volume density. Results with $\mathrm{PV}-1-\mathrm{CB}-1-$ were almost identical to results obtained for $\mathrm{PV}-/-$, clearly demonstrating that the observed effect on mitochondrial volume density increase was PV-specific. Mitochondrial populations can be dis- tinguished by their intracellular localization and distinct functions (Collins et al., 2001; Park et al., 2001). Thus, we postulated that mitochondrial upregulation in PV-I- PC somata could be restricted to mitochondria particularly exposed to $\mathrm{Ca}^{2+}$ fluxes via transport systems in the plasma membrane. In line with the above hypothesis, mitochondrial volume density in the peripheral region within a subplasmalemmal cytoplasmic compartment of $1.5 \mu \mathrm{m}$ was almost doubled in $\mathrm{PV}-{ }_{-}-$ cells (Table 1), while the volume density of central mitochondria was not different between WT and PV - I- PC. Immunofluorescence on cerebellar cryosections (30 $\mu \mathrm{m})$ with $\mathrm{CB}$ antibodies, staining the cytosol in somata, dendrites and spines of $\mathrm{PC}$ and with COX I antibodies staining mitochondria was performed followed by 3D-reconstruction (Fig. 3). Qualitative analyses revealed that more mitochondria were present in the peripheral region of $P C$ somata, in line with the morphometric analysis of EM pictures. Since under pathological conditions such as excitotoxicity, a swelling and rounding up of mitochondria is observed (Bendotti et al., 2001; Pivovarova et al., 2004), the morphology of the peripheral mitochondria was investigated on high-resolution EM images (Fig. 4). No signs of "swollen" mitochondria characterized by electron-lucent matrix, distorted cristae or calcium deposits were observed in the SPL region of PV $-/-\mathrm{PC}$ somata and mitochondria appeared structurally indistinguishable from the ones in WT PC.

Finally we were interested to see whether upregulation of mitochondrial volume density also occurred in subplasmalemmal regions of $\mathrm{PV}-1-\mathrm{PC}$ distal dendritic sites (terminal branchlets), putative sites of $\mathrm{Ca}^{2+}$ entry from the extracellular space. Due to the complex morphology of these structures morphometric analysis of the respective mitochondrial volume densities at the ultrastructural level turned out to be unfeasible. As an alternative, the measurements were 3D-reconstructions using the confocal laser-scanning microscope that allowed a semi-quantitative analysis of the mitochondrial volume in dendritic segments. A box plot for the mitochondrial fractional volume in eight terminal dendrites from two WT mice and 12 terminal

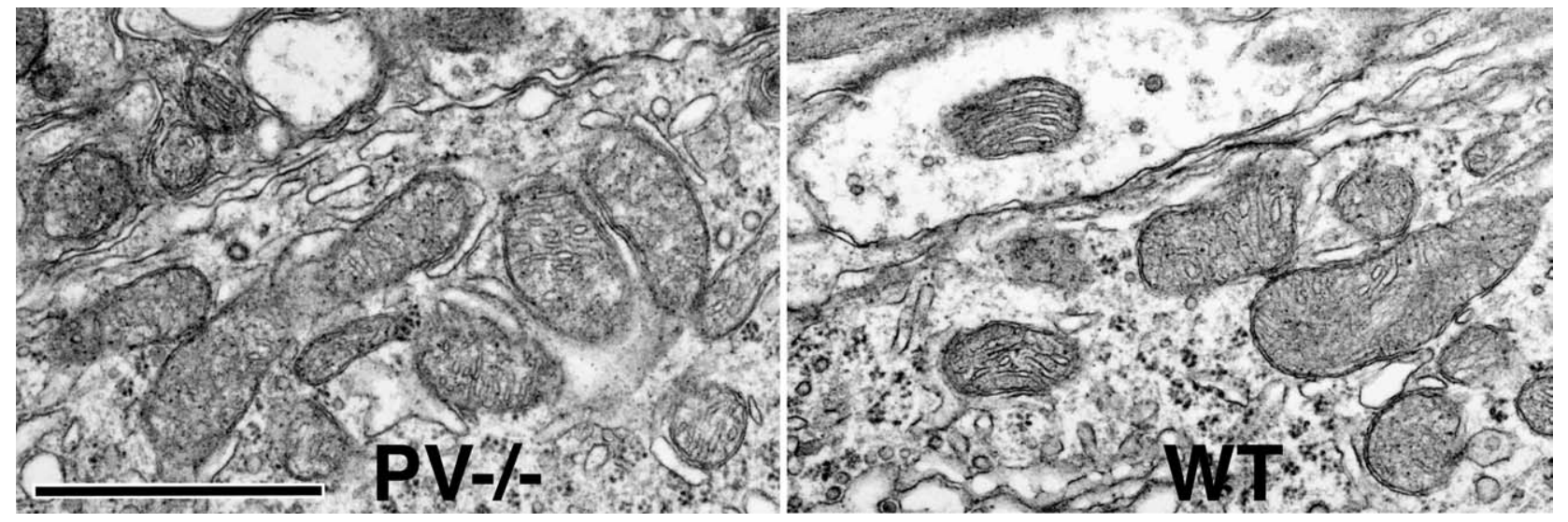

Fig. 4. Electron micrograph of sPL PC somata regions. In both images the plasma membrane runs from the middle of the left side to the right upper corner of each image. SPL PC mitochondria are in the lower part of the images. Note the similar mitochondria morphology in PV - I- and WT PC. Neither swelling, electron-lucent matrix nor deposits are seen in mitochondria of both images. Scale bar=1 $\mu \mathrm{m}$. 


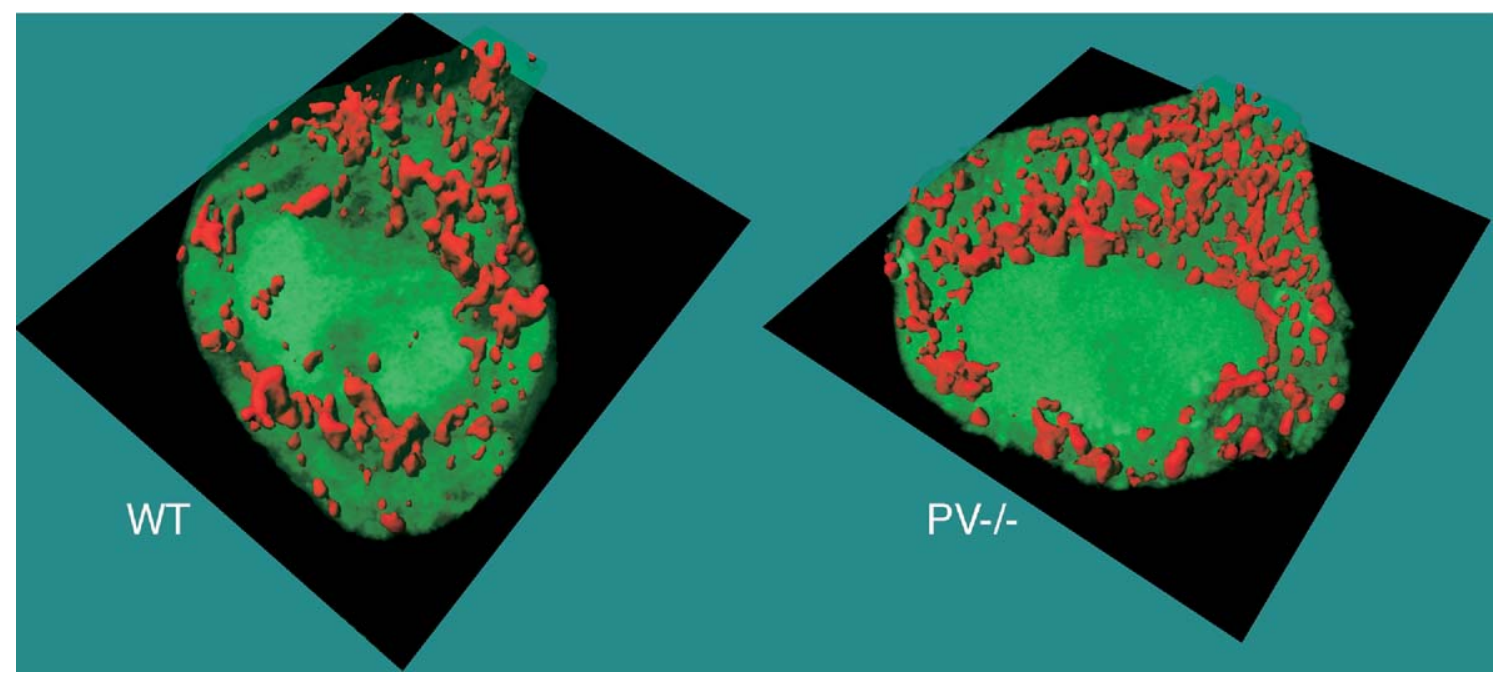

Fig. 3. 3D-reconstruction of a stack of confocal images $(\Delta z=2 \mu \mathrm{m})$ from PC somata of a WT and a PV-l- mouse. Mitochondrial volume (red) is highlighted on a single optical section of the soma. The cytosolic volume (green) was rendered almost transparent. Mitochondria and cytosol were immunostained with anti-COX I and anti-CB antibodies, respectively. Note the increased density of mitochondria close to the plasma membrane in the PV $-1-$ cell.

dendrites from three $\mathrm{PV}-/-$ mice, showed the volume to vary considerably from approximately $7-42 \%$ (Fig. 5). No significant differences between WT and PV $-/$ - terminals could be observed as corroborated by a non-parametric Mann-Whitney $U$ test $(P=0.82)$. To ascertain that mitochondrial volumes calculated from 3D-reconstructions did not introduce artifactual errors, single images from confocal image stacks were also analyzed by design-based stereology (Cavalieri estimator and area fraction fractionator estimator). Mitochondrial volumes calculated in this way were not significantly different from the ones obtained by 3D-reconstruction (not shown) and again were not different between $\mathrm{PV}-\mathrm{I}-$ and $\mathrm{WT}$.

\section{Analysis of sPL-sER}

Although the ER extends throughout the cell, the membraneenclosed cisternae just underneath the plasma membrane termed SPL-sER or when in close apposition to the plasma membrane, also called "junctional ER" (jER) has been implicated in specific functions related to $\mathrm{Ca}^{2+}$ fluxes (Graier et al., 1998; Frieden et al., 2002; Malli et al., 2003). Since an almost twofold increase in peripheral mitochondrial volume density was observed, we investigated, whether additionally changes in SPL-SER have occurred in PC somata of mice deficient for $\mathrm{PV}, \mathrm{CB}$ or both. In a zone of $0.5 \mu \mathrm{m}$ in width underneath the plasma membrane the surface of SPL-sER
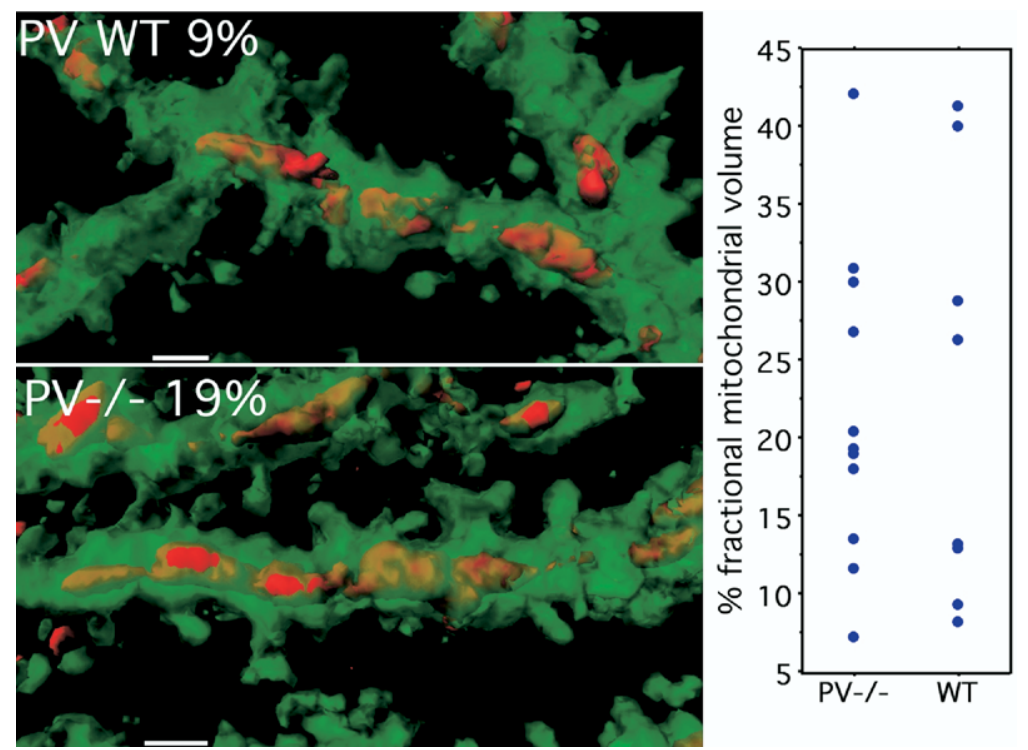

Fig. 5. 3D-reconstruction of two terminal dendrites with low (9\%) and medium (19\%) fractional mitochondrial volume from PC confocal images of a WT and a PV-I- mouse, respectively. The cytosolic volume was visualized by staining for CB (green), the mitochondrial volume by staining for COX I (red). A scatter plot showing the percentage of fractional mitochondrial volume of terminal dendrites for the two genotypes is shown on the right. The geometric mean was not different for the two groups $(P=0.81)$. Scale bar=1 $\mu \mathrm{m}$. 
Table 1. (A) Total mitochondrial volume density in PC somata

\begin{tabular}{lccccc}
\hline Genotype & $n$ & $\mathrm{n}(\mathrm{PC})$ & $\%\left(\mathrm{~V}_{\mathrm{Vmi}, \mathrm{c}}\right) \pm \mathrm{SD}$ & $\%$ Control & $P(\mathrm{vs} . \mathrm{WT})$ \\
\hline WT & 4 & 240 & $8.89 \pm 0.21$ & 100 & - \\
PV-I- & 4 & 240 & $12.80 \pm 0.38$ & 144 & $P<0.001$ \\
CB-I- & 3 & 180 & $8.71 \pm 0.36$ & 98 & - \\
PV-I-CB-I- & 3 & 180 & $12.75 \pm 0.44$ & 143 & n.s.
\end{tabular}

(B) Subplasmalemmal (sPL) and central (CC) compartment mitochondrial volume densities ( $n=4$ animals, 240 PC somata analyzed)

\begin{tabular}{lcccc}
\hline Genotype & $\%\left(\mathrm{~V}_{\mathrm{Vmi}, \mathrm{sPL}}\right)$ & $\%$ Control & $\%\left(\mathrm{~V}_{\mathrm{Vmi}, \mathrm{CC}}\right)$ & \% Control \\
\hline WT & $7.71 \pm 0.50$ & 100 & $10.69 \pm 0.41$ & 100 \\
PV-I- & $13.80 \pm 0.43$ & 178 & $11.13 \pm 0.24$ & 104 \\
& $P<0.001$ & & n.s. & \\
\hline
\end{tabular}

Mean \pm standard deviation; $P$ values (Student's $t$-test; unpaired); $P(\mathrm{CB}-/-\mathrm{vs} . \mathrm{PV}-/-\mathrm{CB}-/-)<0.005$. Values are means $\pm \mathrm{SD}$. In the lowest lanes, respective $P$ values were calculated for differences between $P V-I-$ and WT PC.

$n$, Number of animals; $\mathrm{n}(\mathrm{PC})$, number of PC somata analyzed; n.s., not significant; \%( $\left.\mathrm{V}_{\mathrm{Vmi}, \mathrm{C}}\right)$, volume density of mitochondria in cytoplasm; $\%\left(V_{V m i, s P L}\right)$ and \%( $\left.V_{V m i, C C}\right)$, mitochondrial volume densities in SPL's and CC's of PC's.

per surface of plasma membrane was calculated and this ratio was approximately $30-40 \%$ smaller in PC of PV $-1-$ and double knockout mice (Fig. 6 and Table 2). A small $(<10 \%$; n.s.), yet not significant reduction in this ratio was observed in PC from $\mathrm{CB}-/-$ mice. As for the results obtained from the mitochondrial volume density measurements, the reduction in SPL-sER is specifically correlated with a lack of $\mathrm{PV}$ in both, $\mathrm{PV}-/-$ and $\mathrm{PV}-/-\mathrm{CB}-/-\mathrm{PC}$.

\section{DISCUSSION}

Intracellular $\mathrm{Ca}^{2+}$ homeostasis is precisely regulated with respect to the components involved and their geometrical arrangement within a neuron (Augustine et al., 2003). Cells use components of the " $\mathrm{Ca}^{2+}$-signaling toolkit" (Berridge et al., 2003) to exactly adjust the spatiotemporal aspects of $\mathrm{Ca}^{2+}$ signaling to their physiological function. The importance of cytosolic $\mathrm{Ca}^{2+}$ buffers as essential components in this regulation is a relatively recent discovery. Similarly, mitochondria have experienced a comeback as transient $\mathrm{Ca}^{2+}$ stores also under physiological conditions (Pozzan and Rizzuto, 2000), contrasting the earlier view that these organelles contribute to $\mathrm{Ca}^{2+}$ homeostasis primarily under pathologic conditions (excitotoxicity, apoptosis). Mitochondria participate in $\mathrm{Ca}^{2+}$ removal during muscle relaxation in slow-twitch (Sembrowich et al., 1985; Gillis, 1997) and fast-twitch muscles (Rudolf et al., 2004); in neurons they also contribute to the presynaptic regulation of $\mathrm{Ca}^{2+}$ transients (Billups and Forsythe, 2002). Besides the anticipated slowing of muscle relaxation in $\mathrm{PV}-1-$ mice, a twofold increase in mitochondrial volume density is observed that is viewed as a specific homeostatic compensation mechanism (Chen et al., 2001). Interestingly, the biochemical composition of $\mathrm{PV}-/$ - fast-muscle mitochondria is as found in slow-twitch muscles, characterized by higher expression levels of proteins involved in oxidative phosphorylation (Racay et al., 2006). Thus they are better

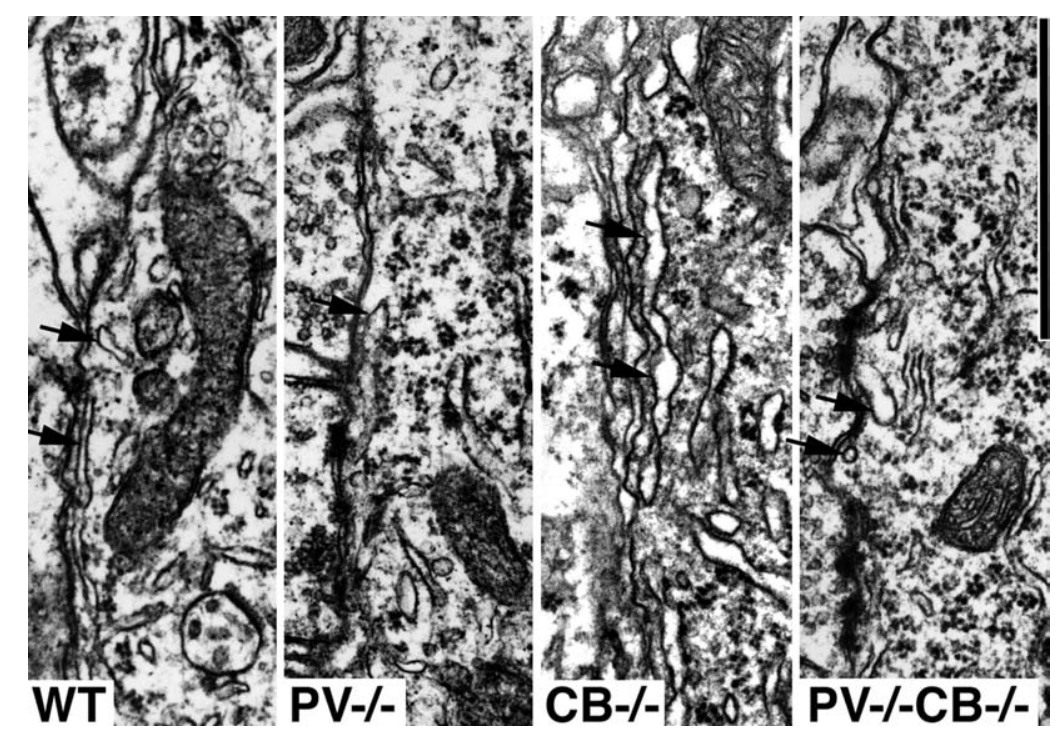

Fig. 6. Electron micrograph of the sPL region of PC somata. Arrows point to "smooth" sPL-sER compartments. Scale bar $=1 \mu \mathrm{m}$ on the right. 
Table 2. Surface ratio of subplasmalemmal $S E R\left(S_{S E R}\right)$ and plasma membrane $\left(S_{P M}\right)$ in $P C$

\begin{tabular}{lllllll}
\hline Genotype & $n$ & $\mathrm{n}(\mathrm{PC})$ & $\mathrm{S}_{\mathrm{SER}} / \mathrm{S}_{\mathrm{PM}} \pm \mathrm{SD}$ & $\%$ Control & $P($ vs. WT) & $P(\mathrm{vs} . \mathrm{PV}-/-$ ) \\
\hline WT & 4 & 40 & $2.55 \pm 0.15$ & 100 & - & $P<0.001$ \\
PV-I- & 4 & 40 & $1.58 \pm 0.11$ & 62 & $P<0.001$ & - \\
CB $-I-$ & 3 & 30 & $2.28 \pm 0.04$ & 89 & n.s. & $P<0.001$ \\
PV $-I-\mathrm{CB}-I-$ & 3 & 30 & $1.77 \pm 0.16$ & 69 & $P=0.001$ & n.s. \\
\hline
\end{tabular}

$P$ values were calculated with Student's $t$-test (unpaired). Differences between $\mathrm{CB}-1-$ and $\mathrm{PV}-1-\mathrm{CB}-1-$ were also significant: $P<0.005$.

$n$, number of animals; $\mathrm{n}(\mathrm{PC})$, number of $\mathrm{PC}$ somata analyzed; n.s., not significant; ${ }_{\mathrm{sER}} / \mathrm{S}_{\mathrm{PM}}$, surface ratio of subplasmalemmal sER and plasma membrane.

suited to uphold the electrochemical potential gradient $\Delta \psi_{\mathrm{m}}$ across the mitochondrial membrane, utilized to drive $\mathrm{Ca}^{2+}$ uptake into these organelles (Duchen, 1999).

Here we set out to investigate how cerebellar PC, neurons with extensive $\mathrm{Ca}^{2+}$ signaling, cope with the absence of PV and CB. Design-based, unbiased morphometry revealed a global $40 \%$ increase in mitochondrial volume density in PV - /- PC somata. Since mitochondria display a large heterogeneity in terms of composition, structure, intracellular localization and function (Meldolesi, 2001; Park et al., 2001; Collins et al., 2002; Mootha et al., 2003), we conjectured that upregulation of mitochondria might be non-random in the PC somata, concentrated at sites of principal $\mathrm{Ca}^{2+}$ entry. Steep elevations of $\left[\mathrm{Ca}^{2+}\right]_{\mathrm{i}}$ with a half-rise time of $50 \mathrm{~ms}$ confined to a submembrane shell of 2- to 3- $\mu \mathrm{m}$ thickness occur after single climbing fiber stimulation (Eilers et al., 1995). The observed increase in PV-I- PC mitochondrial volume density was restricted to the subplasmalemmal region, in line with the hypothesis that these organelles might mainly serve as local $\mathrm{Ca}^{2+}$ stores.

Ultrastructural analysis revealed no signs of "swollen" or otherwise altered SPL mitochondria morphology precluding a pathological condition resulting from $\mathrm{Ca}^{2+}$ overload. The additional peripheral mitochondria might not only serve as transient $\mathrm{Ca}^{2+}$ sinks, but the $\mathrm{Ca}^{2+}$-induced increase in ATP production might be used locally by PMCAs for efficient $\mathrm{Ca}^{2+}$ extrusion following somatic $\mathrm{Ca}^{2+}$ transients as proposed before (Yi et al., 2004). Cytoskeletal elements are involved in transiently stabilizing and adjusting the position of organelles (ER, mitochondria) (Hajnoczky et al., 1994) and, in the case of mitochondria, depend on $\left[\mathrm{Ca}^{2+}\right]_{i}$ (Yi et al., 2004). Mitochondria mobility in cardiac myoblasts is maximal at resting $\left[\mathrm{Ca}^{2+}\right]_{i}$ and complete immobility is observed at 1-2 $\mu \mathrm{M}$. The authors' suggestion that this homeostatic mechanism, i.e. promoting local recruitment of mitochondria that may serve to enhance local $\mathrm{Ca}^{2+}$ buffering and energy supply in cell regions exposed to frequent $\left[\mathrm{Ca}^{2+}\right]_{i}$ rises, is well supported by our findings.

Also sER is structurally and functionally heterogeneous (Blaustein and Golovina, 2001) and a tight interplay between mitochondria, sER compartments and the plasma membrane exists with respect to $\left[\mathrm{Ca}^{2+}\right]_{i}$ modulation (Landolfi et al., 1998). In specialized SPL regions, junctional ER in close proximity to mitochondria exists (Henkart et al., 1976) and local $\mathrm{Ca}^{2+}$ signaling appears to be "independent" of the bulk cytosolic $\mathrm{Ca}^{2+}$ signaling (Arnon et al., 2000). In PV-I- PC somata, sPL-sER compartments were decreased by approximately 35\%. Hence PV-deficiency is compensated in two ways: by increasing subplasmalemmal mitochondria to likely enhance the "slow $\mathrm{Ca}^{2+}$ buffering capacity" and by decreasing SPL-sER to probably reduce the $\mathrm{Ca}^{2+}$ storage or possibly more crucial, diminish the size of a putative source of $\mathrm{Ca}^{2+}$-release. Such a store might release $\left[\mathrm{Ca}^{2+}\right]_{\mathrm{i}}$ via a $\mathrm{IP}_{3}$-mediated mechanism or via $\mathrm{Ca}^{2+}$-induced $\mathrm{Ca}^{2+}$ release (CICR). Metabotropic glutamate receptor-mediated delayed $\mathrm{Ca}^{2+}$ release is essential in PC dendrites and spines (Finch and Augustine, 1998; Takechi et al., 1998), but its putative role in shaping somatic $\mathrm{Ca}^{2+}$ transients is less clear and may be of importance mainly during postnatal PC development (Liljelund et al., 2000; Nelson et al., 2004). We hypothesize that ER-mediated $\mathrm{Ca}^{2+}$ oscillations (waves) are decreasing in parallel to the increase in PV expression also based on results that in oocytes, PV prevents the generation of $\mathrm{IP}_{3}$-induced $\mathrm{Ca}^{2+}$ waves and restricts $\mathrm{Ca}^{2+}$ signals to local $\mathrm{Ca}^{2+}$ release sites (Dargan et al., 2004). Thus one of the functions of somatic PV might be to restrict or even prevent the generation of $\mathrm{Ca}^{2+}$ waves in mature $\mathrm{PC}$, a function also attributed to mitochondria in astrocytes and hepatocytes. Receptor-mediated $\mathrm{ER} \mathrm{Ca}^{2+}$ release in astrocytes results in propagating waves traveling considerably faster when $\left[\mathrm{Ca}^{2+}\right]_{\mathrm{m}}$ uptake is blocked (Boitier et al., 1999). Also in hepatocytes, mitochondria are involved in setting the threshold for activation and defining the subcellular distribution of $\mathrm{IP}_{3}$-dependent $\mathrm{Ca}^{2+}$ signaling (Hajnoczky et al., 1999). In addition the decrease of sPL-ER might result from a redistribution of these structures to regions more distal $(>0.5 \mu \mathrm{m})$ to the plasma membrane, a $\mathrm{Ca}^{2+}$ dependent mechanism previously observed in cultured cells (Subramanian and Meyer, 1997). Such ER repositioning away from $\mathrm{Ca}^{2+}$-entry sites would make these organelles less sensitive to CICR.

Mitochondrial volume density in PC distal dendrites was very heterogeneous, varying by a factor of almost three (e.g. 13-31\%) within PC dendrites from neighboring neurons, but was independent of the genotype. Based on the short-lived nature of climbing fiber-elicited $\mathrm{Ca}^{2+}$ transients in PC spines and dendrites (time to peak: 10-15 ms; initial decay $\tau_{\text {fast }}: 20-30 \mathrm{~ms}$; (Schmidt et al., 2003b) and the slow $\mathrm{Ca}^{2+}$-binding kinetics of $\mathrm{PV}$, this buffer is not expected to play an important role in modulating dendritic $\mathrm{Ca}^{2+}$ transients. Thus its absence in $\mathrm{PV}-/-\mathrm{PC}$ dendrites appears not to necessitate the induction of compensation mechanisms. Much larger differences in the shape of the $\left[\mathrm{Ca}^{2+}\right]_{\mathrm{i}}$ decay exist in $\mathrm{CB}-/-\mathrm{PC}$ dendrites (Schmidt et al., 
2003b) indicative of a more prominent role for CB than for $\mathrm{PV}$ in $\mathrm{Ca}^{2+}$ signaling in dendrites and spines. This is also supported by morphological alterations in spine morphology of $\mathrm{CB}-/-$, but not PV $-/-\mathrm{PC}$ : an increase in the spine volume and the spine length (Vecellio et al., 2000).

The absence of $\mathrm{CB}$ in $\mathrm{CB}-1-\mathrm{PC}$ somata neither increased mitochondrial volume density nor decreased sPL-sER surface. The almost identical results in PV-/and double knockout mice indicate that PV's absence is inducing the morphological alterations. When comparing the properties of CB and PV (Schwaller et al., 2002) and their estimated concentration in PC (100-200 $\mu \mathrm{M}$ for both proteins (Maeda et al., 1999; Schmidt et al., 2003b; Hackney et al., 2005), the $\mathrm{Ca}^{2+}$-binding kinetics appear to be the most distinct feature between the two proteins and are a likely cause for the specific compensation mechanisms induced in PC deficient for either $\mathrm{Ca}^{2+}$ buffer.

Interestingly, an inverse correlation between PV and mitochondrial fractional volume is not restricted to PV - Ifast-twitch muscles and PC. The ectopic expression of PV in transgenic mice (Van Den Bosch et al., 2002) decreases the mitochondria volume density in striatal neurons (Maetzler et al., 2004), a neuron population with a very low percentage of neurons with endogenous PV expression in WT mice. Thus, the regulation of $P V$ and mitochondria volume is operational in both directions. Since no interaction of PV with any other molecule has been reported up to now and $\mathrm{PV}$ in $\mathrm{PC}$ dendrites behaves as a freely mobile molecule (Schmidt et al., 2003a), we propose that slight alterations in the spatiotemporal aspects of $\mathrm{Ca}^{2+}$ transients in the presence or absence of PV are sufficient to regulate subtle, spatially restricted mitochondria biogenesis.

Acknowledgments-The project was supported by the Swiss National Science Foundation (grant 3200-059559.99/1 to M.R.C. and grants $3100-063448.00 / 1$ and $3100 A 0-100400 / 1$ to B.S.). We would like to thank S. Eichenberger for taking care of the animal facilities and W. Graber, University of Bern for preparing the specimen for EM. The help of Dr. J. Eilers, Leipzig for comments and constructive discussions is highly appreciated.

\section{REFERENCES}

Airaksinen MS, Eilers J, Garaschuk O, Thoenen H, Konnerth A, Meyer M (1997) Ataxia and altered dendritic calcium signaling in mice carrying a targeted null mutation of the calbindin D28k gene. Proc Natl Acad Sci U S A 94:1488-1493.

Arnon A, Hamlyn JM, Blaustein MP (2000) Ouabain augments $\mathrm{Ca}(2+)$ transients in arterial smooth muscle without raising cytosolic $\mathrm{Na}(+)$. Am J Physiol Heart Circ Physiol 279:H679-H691.

Augustine GJ, Santamaria F, Tanaka K (2003) Local calcium signaling in neurons. Neuron 40:331-346.

Baba-Aissa F, Raeymaekers L, Wuytack F, Dode L, Casteels R (1998) Distribution and isoform diversity of the organellar $\mathrm{Ca} 2+$ pumps in the brain. Mol Chem Neuropathol 33:199-208.

Bendotti C, Calvaresi N, Chiveri L, Prelle A, Moggio M, Braga M, Silani V, De Biasi S (2001) Early vacuolization and mitochondrial damage in motor neurons of FALS mice are not associated with apoptosis or with changes in cytochrome oxidase histochemical reactivity. J Neurol Sci 191:25-33.

Berridge MJ, Bootman MD, Roderick HL (2003) Calcium signalling: dynamics, homeostasis and remodelling. Nat Rev Mol Cell Biol $4: 517-529$.
Billups B, Forsythe ID (2002) Presynaptic mitochondrial calcium sequestration influences transmission at mammalian central synapses. J Neurosci 22:5840-5847.

Blatow M, Caputi A, Burnashev N, Monyer H, Rozov A (2003) Ca2+ buffer saturation underlies paired pulse facilitation in calbindinD28k-containing terminals. Neuron 38:79-88.

Blaustein MP, Golovina VA (2001) Structural complexity and functional diversity of endoplasmic reticulum $\mathrm{Ca}(2+)$ stores. Trends Neurosci 24:602-608.

Boitier E, Rea R, Duchen MR (1999) Mitochondria exert a negative feedback on the propagation of intracellular $\mathrm{Ca} 2+$ waves in rat cortical astrocytes. J Cell Biol 145:795-808.

Caillard O, Moreno H, Schwaller B, Llano I, Celio MR, Marty A (2000) Role of the calcium-binding protein parvalbumin in short-term synaptic plasticity. Proc Natl Acad Sci U S A 97:13372-13377.

Carafoli E (2002) Calcium signaling: a tale for all seasons. Proc Natl Acad Sci U S A 99:1115-1122.

Celio MR (1990) Calbindin D-28k and parvalbumin in the rat nervous system. Neuroscience 35:375-475.

Chen G, Carroll S, Racay P, Dick J, Pette D, Traub I, Vrbova G, Eggli P, Celio M, Schwaller B (2001) Deficiency in parvalbumin increases fatigue resistance in fast-twitch muscle and upregulates mitochondria. Am J Physiol Cell Physiol 281:C114-C122.

Collins TJ, Berridge MJ, Lipp P, Bootman MD (2002) Mitochondria are morphologically and functionally heterogeneous within cells. EMBO J 21:1616-1627.

Collins TJ, Lipp P, Berridge MJ, Bootman MD (2001) Mitochondrial $\mathrm{Ca}(2+)$ uptake depends on the spatial and temporal profile of cytosolic $\mathrm{Ca}(2+)$ signals. J Biol Chem 276:26411-26420.

Dargan SL, Schwaller B, Parker I (2004) Spatiotemporal patterning of IP3-mediated Ca2+ signals in Xenopus oocytes by $\mathrm{Ca} 2+$-binding proteins. J Physiol 556:447-461.

Duchen MR (1999) Contributions of mitochondria to animal physiology: from homeostatic sensor to calcium signalling and cell death. J Physiol (Lond) 516:1-17.

Eilers J, Callewaert G, Armstrong C, Konnerth A (1995) Calcium signaling in a narrow somatic submembrane shell during synaptic activity in cerebellar Purkinje neurons. Proc Natl Acad Sci U S A 92:10272-10276.

Fierro L, DiPolo R, Llano I (1998) Intracellular calcium clearance in Purkinje cell somata from rat cerebellar slices. J Physiol 510: 499-512.

Fierro L, Llano I (1996) High endogenous calcium buffering in Purkinje cells from rat cerebellar slices. J Physiol 496:617-625.

Filoteo AG, Elwess NL, Enyedi A, Caride A, Aung HH, Penniston JT (1997) Plasma membrane Ca2+ pump in rat brain. Patterns of alternative splices seen by isoform-specific antibodies. J Biol Chem 272:23741-23747.

Finch EA, Augustine GJ (1998) Local calcium signalling by inositol1,4,5-trisphosphate in Purkinje cell dendrites. Nature 396:753756.

Frieden M, Malli R, Samardzija M, Demaurex N, Graier WF (2002) Subplasmalemmal endoplasmic reticulum controls $\mathrm{K}(\mathrm{Ca})$ channel activity upon stimulation with a moderate histamine concentration in a human umbilical vein endothelial cell line. J Physiol 540:73-84.

Gillis JM (1997) Inhibition of mitochondrial calcium uptake slows down relaxation in mitochondria-rich skeletal muscles. J Muscle Res Cell Motil 18:473-483.

Graier WF, Paltauf-Doburzynska J, Hill BJ, Fleischhacker E, Hoebel BG, Kostner GM, Sturek M (1998) Submaximal stimulation of porcine endothelial cells causes focal $\mathrm{Ca} 2+$ elevation beneath the cell membrane. J Physiol 506:109-125.

Hackney CM, Mahendrasingam S, Penn A, Fettiplace R (2005) The concentrations of calcium buffering proteins in mammalian cochlear hair cells. J Neurosci 25:7867-7875. 
Hajnoczky G, Hager R, Thomas AP (1999) Mitochondria suppress local feedback activation of inositol 1,4,5-trisphosphate receptors by $\mathrm{Ca} 2+$. J Biol Chem 274:14157-14162.

Hajnoczky G, Lin C, Thomas AP (1994) Luminal communication between intracellular calcium stores modulated by GTP and the cytoskeleton. J Biol Chem 269:10280-10287.

Henkart M, Landis DM, Reese TS (1976) Similarity of junctions between plasma membranes and endoplasmic reticulum in muscle and neurons. J Cell Biol 70:338-347.

Lander ES et al. (2001) Initial sequencing and analysis of the human genome. Nature 409:860-921.

Landolfi B, Curci S, Debellis L, Pozzan T, Hofer AM (1998) Ca2+ homeostasis in the agonist-sensitive internal store: functional interactions between mitochondria and the ER measured in situ in intact cells. J Cell Biol 142:1235-1243.

Langen H, Roder D, Juranville JF, Fountoulakis M (1997) Effect of protein application mode and acrylamide concentration on the resolution of protein spots separated by two-dimensional gel electrophoresis. Electrophoresis 18:2085-2090.

Lee SH, Schwaller B, Neher E (2000) Kinetics of Ca2+ binding to parvalbumin in bovine chromaffin cells: implications for [Ca2+] transients of neuronal dendrites. J Physiol 525 (Pt 2):419-432.

Liljelund P, Netzeband JG, Gruol DL (2000) L-type calcium channels mediate calcium oscillations in early postnatal Purkinje neurons. J Neurosci 20:7394-7403.

Maeda H, Ellis-Davies GC, Ito K, Miyashita Y, Kasai H (1999) Supralinear $\mathrm{Ca} 2+$ signaling by cooperative and mobile $\mathrm{Ca} 2+$ buffering in Purkinje neurons. Neuron 24:989-1002.

Maetzler W, Nitsch C, Bendfeldt K, Racay P, Vollenweider F, Schwaller B (2004) Ectopic parvalbumin expression in mouse forebrain neurons increases excitotoxic injury provoked by ibotenic acid injection into the striatum. Exp Neurol 186:78-88.

Malli R, Frieden M, Osibow K, Graier WF (2003) Mitochondria efficiently buffer subplasmalemmal $\mathrm{Ca} 2+$ elevation during agonist stimulation. J Biol Chem 278:10807-10815.

Maruyama K, Mikawa T, Ebashi S (1984) Detection of calcium binding proteins by $45 \mathrm{Ca}$ autoradiography on nitrocellulose membrane after sodium dodecyl sulfate gel electrophoresis. J Biochem (Tokyo) 95:511-519.

Meldolesi J (2001) Rapidly exchanging Ca2+ stores in neurons: molecular, structural and functional properties. Prog Neurobiol 65: 309-338.

Mootha VK, Bunkenborg J, Olsen JV, Hjerrild M, Wisniewski JR, Stahl E, Bolouri MS, Ray HN, Sihag S, Kamal M, Patterson N, Lander ES, Mann M (2003) Integrated analysis of protein composition, tissue diversity, and gene regulation in mouse mitochondria. Cell 115:629-640.

Nagerl UV, Novo D, Mody I, Vergara JL (2000) Binding kinetics of calbindin- $\mathrm{D}(28 \mathrm{k})$ determined by flash photolysis of caged $\mathrm{Ca}(2+)$. Biophys J 79:3009-3018.

Nelson TE, Netzeband JG, Gruol DL (2004) Chronic interleukin-6 exposure alters metabotropic glutamate receptor-activated calcium signalling in cerebellar Purkinje neurons. Eur $\mathrm{J}$ Neurosci 20:2387-2400.

Park MK, Ashby MC, Erdemli G, Petersen OH, Tepikin AV (2001) Perinuclear, perigranular and sub-plasmalemmal mitochondria have distinct functions in the regulation of cellular calcium transport. EMBO J 20:1863-1874.

Pivovarova NB, Nguyen HV, Winters CA, Brantner CA, Smith CL, Andrews SB (2004) Excitotoxic calcium overload in a subpopulation of mitochondria triggers delayed death in hippocampal neurons. J Neurosci 24:5611-5622.

Pozzan T, Rizzuto R (2000) High tide of calcium in mitochondria. Nat Cell Biol 2:E25-E27.
Racay P, Gregory P, Schwaller B (2006) Parvalbumin deficiency in fast-twitch muscles leads to increased "slow-twitch type" mitochondria, but does not affect the expression of fiber specific proteins. FEBS J 273:96-108.

Rudolf R, Mongillo M, Magalhaes PJ, Pozzan T (2004) In vivo monitoring of $\mathrm{Ca}(2+)$ uptake into mitochondria of mouse skeletal muscle during contraction. J Cell Biol 166:527-536.

Schmidt H, Brown EB, Schwaller B, Eilers J (2003a) Diffusional mobility of parvalbumin in spiny dendrites of cerebellar Purkinje neurons quantified by fluorescence recovery after photobleaching. Biophys J 84:2599-2608.

Schmidt H, Stiefel KM, Racay P, Schwaller B, Eilers J (2003b) Mutational analysis of dendritic Ca2+ kinetics in rodent Purkinje cells: role of parvalbumin and calbindin D28k. J Physiol 551:13-32.

Schwaller B, Dick J, Dhoot G, Carroll S, Vrbova G, Nicotera P, Pette D, Wyss A, Bluethmann H, Hunziker W, Celio MR (1999) Prolonged contraction-relaxation cycle of fast-twitch muscles in parvalbumin knockout mice. Am J Physiol Cell Physiol 276:C395C403.

Schwaller B, Meyer M, Schiffmann SN (2002) "New" functions for "old" proteins: The role of the calcium-binding proteins calbindin D-28k, calretinin and parvalbumin, in cerebellar physiology. Studies with knockout mice. Cerebellum 1:241-258.

Sembrowich WL, Quintinskie JJ, Li G (1985) Calcium uptake in mitochondria from different skeletal muscle types. J Appl Physiol 59: 137-141.

Stauffer T, Guerini D, Celio M, Carafoli E (1997) Immunolocalization of the plasma membrane $\mathrm{Ca}++$ pump isoforms in the rat brain. Brain Res 748:21-29.

Stauffer TP, Guerini D, Carafoli E (1995) Tissue distribution of the four gene products of the plasma membrane $\mathrm{Ca} 2+$ pump. A study using specific antibodies. J Biol Chem 270:12184-12190.

Subramanian K, Meyer T (1997) Calcium-induced restructuring of nuclear envelope and endoplasmic reticulum calcium stores. Cell 89:963-971.

Takechi H, Eilers J, Konnerth A (1998) A new class of synaptic response involving calcium release in dendritic spines. Nature 396: 757-760.

Van Den Bosch L, Schwaller B, Vleminckx V, Meijers B, Stork S, Ruehlicke T, Van Houtte E, Klaassen H, Celio MR, Missiaen L, Robberecht W, Berchtold MW (2002) Protective effect of parvalbumin on excitotoxic motor neuron death. Exp Neurol 174: 150-161.

Vecellio M, Schwaller B, Meyer M, Hunziker W, Celio MR (2000) Alterations in Purkinje cell spines of calbindin D-28 k and parvalbumin knock-out mice. Eur J Neurosci 12:945-954.

Vreugdenhil M, Jefferys JGR, Celio MR, Schwaller B (2003) Parvalbumin-deficiency facilitates repetitive IPSCs and gamma oscillations in the hippocampus. J Neurophysiol 89:1414-1422.

Weibel ER (1979) Sterological methods, Vol. 1: practical methods for biological morphometry. London: Academic Press.

Wuytack F, Eggermont JA, Raeymaekers L, Plessers L, Casteels R (1989) Antibodies against the non-muscle isoform of the endoplasmic reticulum Ca2(+)-transport ATPase. Biochem J 264:765-769.

Yi M, Weaver D, Hajnoczky G (2004) Control of mitochondrial motility and distribution by the calcium signal: a homeostatic circuit. J Cell Biol 167:661-672.

\section{APPENDIX}

\section{Supplementary data}

Supplementary data associated with this article can be found, in the online version, at doi:10.1016/j.neuroscience.2006.06.008. 